\title{
CRYPTOCOCCOSIS:
}

\section{TWO CASES IN MILITARY HOSPITALS IN BRITAIN}

\author{
Major C. M. CHABREL, M.A., M.B., B.Chir., M.R.C.S., L.R.C.P., R.A.M.C. * \\ Major D. M. WAYTE, M.D., M.R.C.Path., D.Path., D.T.M. \& H., R.A.M.C. $\dagger$ \\ Royal Army Medical College
}

SUMMARY: Two patients with cryptococcosis of differing clinical types were seen in military hospitals in Britain. The first, a Gurkha soldier, presented as a solitary lung tumour. Local resection was performed and a histological diagnosis made. No further treatment was considered necessary, the patient showed a satisfactory response and there has been no evidence of relapse in almost three years. The second patient, a British soldier undergoing cytotoxic and radiotherapeutic treatment for Hodgkin's disease developed signs of meningo-encephalitis. High doses of steroids, cytotoxic drug therapy and further radiotherapy to the base of the skull failed to induce a clinical improvement. A histopathological diagnosis of systemic cryptococcosis with meningo-encephalitis was made post-mortem.

It is imperative that clinicians and pathologists develop an awareness of systemic mycotic infections particularly those developing as opportunistic infections when cellular immunity and surveillance are compromised either by disease including the malignant lymphomas, leukaemias and sarcoidosis or iatrogenically by steroid, antimetabolite and antibiotic therapy.

\section{Introduction}

There has been an increase in the number of deep mycotic infections diagnosed in Britain in recent years. This increase can be accounted for by:

(a) A greater awareness of such infections, by both clinicians and pathologists. (b) Human immigration from tropical countries where such infections are common. (c) The introduction of antimetabolites, steroids and antibiotics which allow opportunistic fungi to establish themselves, particularly in those cases where cellular immunity has already been compromised as in the malignant lymphomas, leukaemia and sarcoidosis.

This paper reports two cases of cryptococcosis seen at the Army Histopathology Registry within the space of one month, which demonstrate the two major modes of presentation of this infection.

(a) Solitary lung focus in a Gurkha soldier from Nepal. (b) Meningo-encephalitis and systemic infection in a British soldier undergoing treatment for Hodgkin's disease.

\section{Case reports}

Case 1. In December 1968, a 25 year old Gurkha soldier was found to have a discrete, rounded opacity ( $1.5 \mathrm{~cm}$ diameter) in the lateral, mid-zone of his right lung at a routine

* Now Pathalogical Department, ANZUK Military Hospital, Singapore.

$\dagger$ Now Lt. Col. D. M. Wayte (Retd.), 9 Bryn Golau, Bangor, Caerns. 
check X-ray (Mass miniature radiography) in Hong Kong. An earlier chest X-ray in January 1966 had been negative. Tomography in February 1969 confirmed a round shadow of less than calcium density, with a clear area at its summit, in the apical segment of the right lower lobe. At no time did this man complain of symptoms, nor were positive physical signs demonstrated by clinical examination. His E.S.R. remained constant below $5 \mathrm{~mm} / \mathrm{h}$ and his haemoglobin and white cell count were always in the normal range. However, a persistent eosinophilia of around 6 per cent was noted. A positive Casoni skin test was associated with an hydatid complement fixation titre of only 1:4 (doubtful significance). Stool examination showed ova of Trichuris trichiura on one occasion. A Heaf test reading of Grade I was obtained and acid-fast bacilli were never isolated from sputum or urine despite repeated attempts. No change in the opacity in the right lung was observed up to September 1969 and the patient was transferred to the Cambridge Military Hospital, Aldershot, where a thoracotomy was performed in October 1969. Almost total obliteration of the right pleural space by fine adhesions was found and there was a firm nodule $(2 \mathrm{~cm}$ diameter) on the lateral, posterior surface of the right lower lobe. A wedge-shaped lung biopsy $(3.5 \times 2 \mathrm{~cm})$ from the right lower lobe enclosed a cystic cavity filled with mucoid, gelatinous material and in a direct film Cryptococcus neoformans was seen. Further microscopy confirmed yeast bodies within areas of necrotic lung parenchyma and associated with a predominantly lymphocytic response. No metastatic cryptococcal lesions were demonstrated despite a skeletal survey and antimycotic therapy was therefore not thought to be indicated. The patient was returned to Hong Kong and is well at the time of writing (March 1971).

Case 2. A 19 year old soldier presented in April 1969 with left progressive cervical lymphadenopathy. Between the ages of 10 and 14 years he had attended a hospital in the Midlands for a swelling in the right side of his neck. A biopsy when he was aged 13 had led to a diagnosis of Hodgkin's disease and he was treated with a course of radiotherapy to his neck for four weeks. He was seen regularly until 1966 when he remained apparently well. In 1968 he joined the Army at which time his previous history was not revealed. Shortly after enlistment he noticed a " gland" on the left side of his neck. During the next year this progressed to a chain of glands which became tender three months prior to his hospital admission in April 1969. Biopsy of the nodes at this time showed destruction of lymph node architecture by sheets of pleomorphic cells with giant cells and characteristic Reed-Sternberg cells. A diagnosis of Hodgkin's lymphoma was made. At this time the patient's spleen was just palpable and his chest X-ray showed no hilar enlargements. Tests showed $\mathrm{Hb} 14.2 \mathrm{~g} / 100 \mathrm{ml}$; W.B.C. $4000 / \mathrm{mm}^{3}$, with a normal differential count; E.S.R. $5 \mathrm{~mm} / \mathrm{h}$ (Westergren). Treatment with intravenous Mustine Hydrochloride over ten days to a total of $30 \mathrm{mg}$ was commenced on 18 April 1969. After this course the patient's cell count fell to $2400 / \mathrm{mm}^{3}$ on 30 April. Lymphangiography on 22/23 April 1969 showed enlarged para-aortic glands and an appearance consistent with lymphomatous disease. During the following three weeks the patient complained of increased swelling of his left cervical glands with discomfort in the region of the left shoulder and axilla. He did not suffer with pruritus or alcohol intolerance but he did have night sweats. Treatment with intravenous Vinblastine Sulphate (Velbe) was commenced on 22 May $1969(6 \mathrm{mg})$, and his subsequent medication, radiotherapy and white cell counts are shown in Table I. On 24 August 1969 the patient began to suffer from headaches, initially frontal but later generalised and which were without 
localising neurological signs. The development of definitive meningism with bilateral papilloedema by $4 / 5$ September was followed by VI and partial III cranial nerve palsies. The cerebrospinal fluid on 26 August contained 16 lymphocytes $/ \mathrm{mm}^{3}$ with $30 \mathrm{mg} / 100$ $\mathrm{ml}$ of protein at a pressure of $250 \mathrm{~mm}$ fluid. No organisms were seen on microscopy (although an indian ink preparation was not studied) and no bacterial growth was obtained. Treatment (Table I) with Dexamethasone, cytotoxic drugs and radiotherapy

Table I

Calendar of treatment for Case 2 with Hodgkin's disease

\begin{tabular}{|c|c|c|c|c|}
\hline $\begin{array}{c}\text { Date } \\
\text { (year 1969) }\end{array}$ & $\begin{array}{l}\text { Cytotoxic drugs } \\
\text { (intravenous) }\end{array}$ & $\begin{array}{c}\text { Steroids } \\
\text { (Dexamethasone) }\end{array}$ & Radiotherapy & $\begin{array}{l}\text { W.B.C. } \\
\left(\text { per } \mathrm{mm}^{3}\right)\end{array}$ \\
\hline $\begin{array}{l}\text { May } 22 \\
\text { May } 23 \\
\text { May } 29 \\
\text { May } 30 \\
\text { June } 6 \\
\text { June } 8 \\
\text { June } 10 \\
\text { June } 12 \\
\text { June } 18 \\
\text { June } 19 \text { to } \\
\text { July } 14 \\
\text { August } 13 \\
\text { September } 5 \\
\text { September } 8 \\
\text { to } 18 \\
\text { September } 15 \\
\text { September } 17 \\
\\
\text { September } 18 \\
\text { September } 20\end{array}$ & 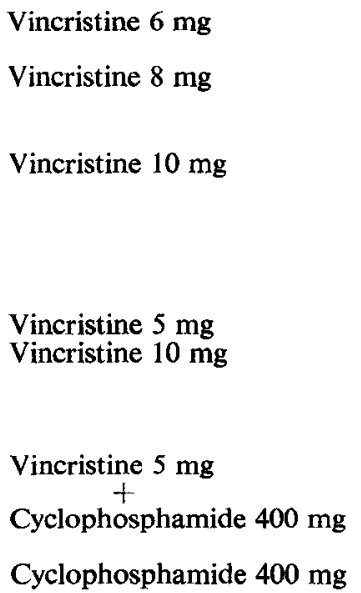 & $\begin{array}{l}1 \mathrm{mg} \text { t.d.s. } \\
2 \mathrm{mg} \text { t.d.s. } \\
10 \mathrm{mg} \text { b.d. } \\
5 \mathrm{mg} \text { q.d.s. }\end{array}$ & $\begin{array}{l}3600 \text { rads to left } \\
\text { side of neck } \\
1250 \text { rads to } \\
\text { brain stem }\end{array}$ & $\begin{array}{l}5000 \\
\\
3300 \\
5400 \\
\\
3400 \\
1200 \\
3200 \\
\\
\\
4200 \\
5000\end{array}$ \\
\hline
\end{tabular}

to the base of the skull produced no improvement. His condition continued to deteriorate and he died on 24 September 1969, approximately 1 month after the onset of the headaches. At post mortem there was no macroscopic evidence of meningitis or of lymphomatous deposition and the only lymphadenopathy found was along the abdominal aorta. Microscopically however, the meninges were seen to be diffusely infiltrated by lymphocytes associated with multiple cryptococci whose mucinous capsules stained positively (red) with mucicarmine. Deep penetration by the yeasts into the sulci and around the superficial capillaries of the cerebral cortex and cerebellum were seen. The organisms were also found in small numbers in the liver within the portal tracts. They were not seen in the lungs. Hodgkin's granuloma with characteristic Reed-Sternberg cells was present in the spleen and lymph nodes along the abdominal aorta. After the diagnosis of cryptococcosis had been made direct inquiry did not reveal any particular association between the patient and pigeons.

The organism

\section{Discussion}

A saprophyte organism, later identified as Cryptococcus neoformans was first isolated in Sardinia by Sanfelice (1894) who also demonstrated the "neoformans" (tumour forming) properties of the organism in animal experiments. Almost simul- 
taneously with its isolation as a saprophyte, a case of clinical infection was described in Germany (Busse 1894).

It was not until 1930 that the disease was first described in Britain (Smith and Crawford 1930). At this time the organism was known as Torula histolytica but since the recommendation of the medical Mycology Committee of the Medical Research Council in 1967, the name Cryptococcus neoformans has been preferred. There is still controversy at the present time as to whether there exists only one, or many, species of the organism. (Castellani 1969).

Cryptococcus neoformans is an ubiquitious saprophyte. The first isolation was from fermenting peach juice and it has subsequently been isolated from soil on many occasions (Ajello 1958). Pigeon faeces are an abundant reservoir (Emmons 1960) of the organism, because of their high content of creatinine which is a nitrogen source for Cryptococcus neoformans. Pigeon droppings in London are a reliable source of the fungus (Annotation 1965). It should be noted that both the pigeon and rabbit are immune to clinical infection. However, many animals are known to develop cryptococcosis and these include cats and koala bears (Frey and Durie 1964). It has been incriminated as a cause of bovine mastitis.

The organism grows luxuriantly at $37^{\circ} \mathrm{C}$ but temperatures above $40^{\circ} \mathrm{C}$ inhibit it. This may account for the rabbit's (body temperature $39.6^{\circ} \mathrm{C}$ ) resistance to this infection and the failure to incriminate birds as a possible host.

Recently Shadomy (1970) established that Cryptococcus neoformans is a Basidiomycete and is placed in the genus Leucosporidium (Leucosporidium neoformans) having noted that some strains produced short septate hyphae, clamp connections, teliospores and basidiospores.

It therefore seems likely that this particular fungus has at last achieved its correct name having passed through such terms as Saccharomyces neoformans, Cryptococcus hominis, Torula histolytica and Cryptococcus neoformans.

\section{Clinical disease}

In regard to human cryptococcal infections there are few accurate or reliable facts available. In the United Kingdom mycotic infections are not notifiable. Figures for the last 3 years from the Mycological Reference Laboratory report from 3 to 5 cases annually (Public Health Laboratory Service 1970). In 1967 Symmers (1968) reported 56 cases occurring in the United Kingdom over a period of 20 years.

Cryptococcosis occurs in both tropical and temperate climates, shows no occupational connection, affects all ages and has no outstanding sex distribution. There is no evidence that spread occurs from man to man or from laboratory-infected animals to man. The primary site of entry for the organism is considered to be the lung, but in the majority of cases pulmonary disease is not recognised and undergoes complete spontaneous resolution. Occasionally isolated, subpleural, granulomata may remain to indicate the site of primary infection. In susceptible hosts, the cryptococcus may produce single or multiple, tumourous lesions ('toruloma') consisting of accummulations of yeast cells with their mucinous capsules. Commonly as in Case 1, there is little or no reaction to the organism and surrounding lymphocytes and plasma cells may or may not be present. Should dissemination occur producing systemic cryptococcosis, 
the central nervous system is the tissue most commonly involved. A predilection for the brain and meninges may reflect the fact that the cerebro-spinal fluid is an optimum growth medium (for example, high thiamine concentration) together with diminished immune activity at this site. Central nervous system involvement usually presents as a refractory, subacute meningitis with non-specific signs.

At autopsy a gelatinous exudate containing large numbers of yeasts may be present at the base of the brain (The absence of obvious exudate in Case 2 may have been the result of steroid therapy and radiotherapy to the skull). Cutaneous manifestations may occur and range from a macular or acneform rash to granulomatous ulceration and abscess formation.

Symmers (1968) also emphasised the increased incidence of cryptococcosis in patients with diseases of the reticulo-endothelial system and particularly Hodgkin's disease. Systemic dissemination in patients is a particular hazard if they are receiving steroids as part of their therapy (Wilson et al 1970).

Experimental studies in mice showed the ability of steroids and X-irradiation to cause dissemination of cryptococcosis from a localised site (Levine, Zimmerman and Scarza 1957). Incrimination of steroid therapy as a predisposing factor for cryptococcal infection is usually related to long-term dosage. In our Case 2, symptoms of meningitis antedated by two weeks, therapy with Dexamethasone.

\section{Laboratory investigations}

A pre-requisite for the clinical diagnosis of fungal disease is clinical suspicion and this is specially so for cryptococcosis. A specific diagnosis of cryptococcosis depending on microscopic or cultural isolation may only be made if the clinician is alert to the possibility of such a disease process. Cryptococcus neoformans exists as rounded or ovoid cells approximately 4 to 20 microns in diameter. The yeast has a thick mucinous capsule which is translucent in wet preparations, is outlined clearly by negative staining with indian ink or nigrosin and easily demonstrable by mucin stains. Examination of cerebro-spinal fluid by such a technique is essential otherwise the yeast cells may not be noticed or be counted as lymphocytes or red blood cells. Culture of the organism on Sabouraud's agar produces a characteristic loose runny mucoid growth with a pale buff colour. Cryptococcus neoformans is lethal for mice and produces intra-cerebral lesions with a swelling of the skull which can be identified easily.

Biochemical reactions are not of routine diagnostic value. Complement fixation, tube agglutination, latex slide agglutination and indirect fluorescent antibody techniques have produced more than 90 per cent presumptive diagnosis when two or three tests are employed concurrently (Kaufman 1970, Walter and Jones 1968). Of 75 patients with known cryptococcal disease, only six were negative when tested by both indirect fluorescent antibody and complement fixation techniques (Bindschadler and Bennett 1968). This range of tests reflects the complexity of man's immune response to fungi and the Cryptococcus in particular. There appears to be an inverse relationship between antibody and antigen in a particular host which varies with the stage of the disease. Thus, a severely ill patient may show little evidence of antibody with high levels of antigen, but successful therapy reverses this pattern. Antibodies to the Cryptococcus have been found in individuals who show no evidence of the disease (Warr, Bates and Stone, 
1968). This may represent a low susceptibility to the disease or previous sub-clinical infection. Serum inhibits the growth of Cryptococcus in vitro. This inhibition is reduced (that is, Cryptococcal growth is enhanced) by serum from patients with active Hodgkin's disease (Gadesbusch 1964) and especially if the liver is involved.

In relation to Case 2 we attempted unsuccessfully to isolate Cryptococcus neoformans from the hospital surroundings. Multiple samples were collected from hospital window ledges, roofs near the patient's day room and other sites in the vicinity of the hospital where pigeon droppings were evident. Culture of suspensions of these samples on Sabouraud's agar failed to yield Cryptococcus. This may possibly be a reflection on our technique rather than the lack of fungi in pigeon droppings for Cryptococcus neoformans has frequently been isolated from such a source in London (Annotation 1965). However, Wilson et al (1970) also reported difficulty in isolating the organism from the hospital environment.

Symmers (1968) stressed the value of histological examination of tissue in the diagnosis of deep mycoses and emphasised the necessity for alertness to the possibility of fungal infections. Cryptococcus neoformans is evident in routine haematoxylin and eosin stains. It may also be elegantly demonstrated by special techniques such as Alcian blue and Periodic Acid Schiff, Hale's colloidal iron and Gridley's stain for fungi.

\section{Treatment}

Disseminated cryptococcosis is not uniformly fatal. On treatment with Amphotericin B, 17 out of 31 patients with meningitis were alive 2 to 12 years after diagnosis (Sarosi et al 1969). More recently, 5-fluorocytosine has been effective in one patient (Sarosi et al 1969). Utz et al (1967) record 11 patients with cryptococcal meningitis of whom 9 showed clinical improvement when treated with 5-fluorocytosine. These possibilities emphasise the importance of early diagnosis.

\section{REFERENCES}

AJELLO, L. (1958). Amer. J. Hyg. 67, 72.

BindsChadLER, D. D. and BeNNETT, J. E. (1968). Ann. intern. Med. 69, 45.

BusSe, O. (1894). Zbl. Bakt. I. Abt. Orig. 16, 175.

Castellani, A. (1969). Lancet ii, 648.

EMmons, C. W. (1960). Publ. Hlth Rep. (Wash.) 75, 4, 362.

FreY, D. and Durie, E. B. (1964). Med. J. Aust. 1, 947.

GadebUSCH, H. H. (1964). Antimicrob. Agts. and Chemother. 1, 947.

KaUfman, L. (1970). In Manual of Clinical Microbiology. American Society for Microbiology. Bethesda, Maryland. P. 386.

Annotation (1965). Lancet ii, 1335.

Levine, S., Zimmerman, H. M. and Scarza, A. (1957). Amer. J. Path. 33, 385.

Medical Research Council (1967). Nomenclature of Fungi Pathogenic to Man. Memo No. 23, 3rd ed. H.M.S.O., London.

Public Health Laboratory Service (1970). Communicable Diseases Report 70/13. London.

SANFEliCE, F. (1894). Ann. Igiene. 4, 463.

Sarosi, G. A., Parker, J. D., Doto, I. L. and Tosh, F. E. (1969). Ann. intern. Med. 71, 1079.

Shadomy H. J. (1970). In. Recent Trends in Yeast Research. Atlanta Research Articles, School of Arts and Sciences, Georgia State University.

Smith, F. B. and Crawford, J. S. (1930). J. Path. Bact. 33, 291.

Symmers, W.St.C. (1968). In. 'Systemic Mycoses'. A Ciba Foundation Symposium. London. P 159.

Utz, J. P., Tynes, B.S., Shadomy, H. J., Duma., R. J., Kannan, M. and Mason, K. N. (1967). Antimicrob. Agts and Chemother. 7, 344.

Walter, J. E. and Jones, R. D. (1968). Amer. Rev, resp. Dis. 97, 275.

Warr, W., Bates, J. H. and Stone, A. (1968). Ann. intern. Med. 69, 1109.

Watkins, J. S., Campbell, M. J., Gardner-Medwia, D., Ingham, H. R. and Murray, J. G. (1969). Brit. med. J. iii, 29.

Wilson, T. S., Fleming, W. A., Robinson, F. L. J. and Nicholl, B. (1970). J. clin. Path. $23,657$. 